\title{
A whey-based glutathione-enhancing diet decreases allergen-induced airway contraction in a guinea-pig model of asthma
}

\author{
J. Kloek ${ }^{1}$, E. Mortaz ${ }^{1,2 *}$, I. Van Ark ${ }^{1}$, N. Bloksma ${ }^{1}$, J. Garssen ${ }^{1,3}$, F. P. Nijkamp ${ }^{1}$ and G. Folkerts ${ }^{1}$ \\ ${ }^{1}$ Division of Pharmacology, Utrecht Institute for Pharmaceutical Sciences, Faculty of Sciences, Utrecht University, Utrecht, \\ The Netherlands \\ ${ }^{2}$ Chronic Respiratory Disease Research Center, National Research Institute of Tuberculosis and Lung Disease (NRITLD), \\ Masih Daneshvari Hospital, Shahid Beheshti University of Medical Sciences, Tehran, Iran \\ ${ }^{3}$ Danone Research Centre for Specialised Nutrition, Wageningen, The Netherlands
}

(Received 25 January 2010 - Revised 18 November 2010 - Accepted 22 November 2010 - First published online 8 February 2011)

\section{Abstract}

Since an allergen-induced early asthmatic reaction is likely to be accompanied by oxidative stress and since levels of the endogenous antioxidant glutathione can be enhanced by a whey-based diet (undenatured whey protein concentrate, UWPC), it was investigated whether UWPC could alleviate allergen-induced lung contractions. Guinea pigs were fed water or UWPC twice a day starting at day -3 up to day 20. The animals were sensitised to ovalbumin or received saline on day 0. Serum samples were taken at several days after sensitisation to measure allergen-specific IgG. On day 20, lungs were isolated and perfused with buffer containing the allergen ovalbumin. Airway contractions were assessed, and mediators and indicators for oxidative stress were measured in the lung effluent. Moreover, glutathione levels were determined in the liver. The indicator of oxidative stress and airway contractile mediator, 8 -iso-PGF $2 \alpha$, was increased upon ovalbumin challenge in ovalbumin-sensitised groups. Furthermore, thiobarbituric acid-reactive substances (TBARS) were increased as well. Sensitisation with ovalbumin increased IgG levels from day 12 up to day 20, which were not influenced by the UWPC diet. In contrast, the UWPC diet significantly enhanced glutathione levels in the liver. Moreover, the UWPC diet significantly reduced the ovalbumin-induced anaphylactic response by $45 \%$ and decreased $\mathrm{PGE}_{2}$ levels by $55 \%$ in the effluent fluid. We show for the first time that during anaphylaxis, there is acute oxidative stress in the respiratory tract. The UWPC diet did not influence the sensitisation response to the allergen but did increase endogenous glutathione levels. The UWPC diet profoundly reduces allergen-induced airway constrictions, which opens new avenues for dietary management of allergic diseases.

Key words: Glutathione: Airway contraction: Guinea pigs

Reactive oxygen species play a prominent role in inflammatory lung diseases, including asthma ${ }^{(1)}$. Although the lungs are equipped with a variety of enzymatic and non-enzymatic antioxidant systems, there are indications that asthma is associated with a local oxidant/antioxidant imbalance, particularly during exacerbations of the disease ${ }^{(2)}$. One of the most prominent endogenous antioxidants in the airways is glutathione $(\mathrm{GSH})^{(3)}$. It has been demonstrated in earlier studies that GSH and other low-molecular-weight thiols relax guinea-pig trachea ex vivo ${ }^{(4)}$. In these guinea-pig studies for allergic asthma, it has been shown that the allergen-induced early asthmatic response is paralleled by markedly decreased lung GSH levels ${ }^{(4,5)}$. Moreover, the allergen-induced airway contractions could be prevented by a cell-permeable GSH analogue ${ }^{(5)}$.
To demonstrate the therapeutic relevance of these findings, it would be of interest to enhance GSH levels in vivo. Administration of GSH, however, is not an effective way to increase tissue GSH levels ${ }^{(6)}$, while the GSH prodrug cysteine is not useful because of its toxicity ${ }^{(7,8)}$. The cysteine derivative $\mathrm{N}$-acetylcysteine is not toxic, but its oral bioavailability is poor $^{(9)}$. An alternative way to enhance GSH levels in vivo is the food supplement undenatured whey protein concentrate (UWPC). UWPC is a mixture of proteins rich in $\gamma$-glutamylglycine, a dipeptide which is known to increase intracellular $\mathrm{GSH}^{(10,11)}$. Interestingly, a case report has referred to a patient with obstructive lung diseases whose improvement of pulmonary function and increase in plasma GSH levels could be correlated with UWPC intake ${ }^{(11)}$. Finally, whey protein supplementation seemed to have an effect on the cytokine response in atopic asthma as well ${ }^{(12)}$.

Abbreviations: GSH, glutathione; TBARS, thiobarbituric acid-reactive substances; UWPC, undenatured whey protein concentrate.

*Corresponding author: Dr E. Mortaz, email emortaz@gmail.com 
In the present study, the effect of UWPC was assessed using the above-described ex vivo guinea-pig model of allergic asthma. Guinea pigs were fed a UWPC diet from $3 \mathrm{~d}$ before sensitisation with the allergen onwards until killing 3 weeks later. At that time, allergen-induced contractions of isolated lungs, as well as lung perfusate levels of indicators for oxidative stress and mediator release such as prostaglandins, were measured. Furthermore, total GSH content of the liver was measured. Blood samples were taken before and at regular intervals after sensitisation to determine allergenspecific IgG levels in the serum.

\section{Materials and methods}

\section{Animals}

Male specific pathogen-free Dunkin Hartley guinea pigs (Harlan Nederland, Horst, The Netherlands) weighing 200-250 g at the start of the experiments were housed under controlled conditions and provided with food and water ad libitum. All experiments were approved by the University of Utrecht Committee on the Use and Care of Animals.

\section{Diet regimen}

UWPC (HMS90 purchased by Immunocal; Immunotec Research Limited; Vaudreuil, QC, Canada) was gently dissolved in sterile tap water at a concentration of $0.5 \mathrm{~g} / \mathrm{ml}$ immediately before use. The animals ( $n$ 17) received UPWC per os using a syringe with a polyethylene tubing that was placed at the back of the mouth of the animal. Slowly emptying the syringe made the animals swallow spontaneously. Each animal received $5 \mathrm{ml}$ of whey solution twice daily, with $7 \mathrm{~h}$ between the administrations. Controls ( $n$ 16) received sterile tap water following the same administration regimen. Whey administration started $3 \mathrm{~d}$ before sensitisation.

\section{Ovalbumin sensitisation and challenge}

Animals (water-fed group, $n 7$; UWPC-fed group, $n$ 8) were sensitised on day 0 by injecting a mixture of $20 \mu \mathrm{g}$ ovalbumin (grade V; Sigma, St Louis, MO, USA) and $200 \mathrm{mg}$ of the adjuvant, $\mathrm{Al}(\mathrm{OH})_{3}$ (Merck, Darmstadt, Germany), in $1.0 \mathrm{ml}$ saline. $\mathrm{Al}(\mathrm{OH})_{3}$ in saline was used for sham sensitisation of the control animals (water-fed group, $n$ 9; UWPC-fed group, $n$ 9). Each animal received six injections: $0.5 \mathrm{ml}$ was injected intraperitoneally, and five injections $(0 \cdot 1 \mathrm{ml}$ each) were given subcutaneously in the axillar and inguinal regions and in the nuchal area. On day 20, airways were isolated and challenged ex vivo with ovalbumin as described in the following section. Control animals were treated in the same way, although without ovalbumin. A scheme of the treatment protocol and the parameters that were measured is depicted in Fig. 1.

\section{Tracheally perfused lung preparation}

Tracheal perfusion was performed on day 20 after sensitisation, as previously described ${ }^{(5)}$. Guinea pigs were anaesthetised by

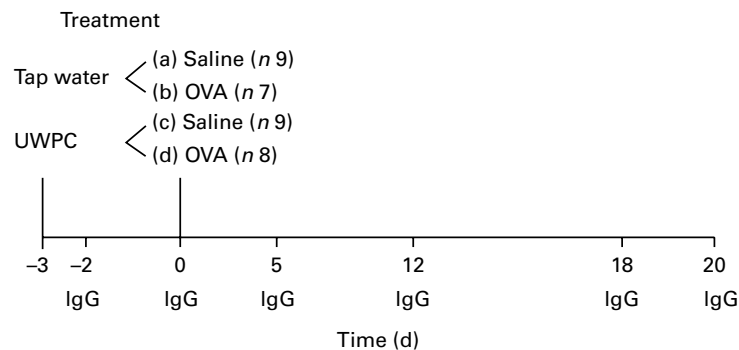

Fig. 1. Overview of the treatments and measured parameters. From day -3 , animals received tap water $(n 16)$ or undenatured whey protein concentrate (UWPC, $n$ 17) twice a day up to day 20 . On day 0 , animals were sensitised with ovalbumin (OVA, $n$ 15) or received saline ( $n$ 18). On days $-3,0,5,12$, 18 and 20, blood samples were taken for IgG. At day 20, the airways were isolated and perfused with a buffer. Airway responses were measured ex vivo after the administration of OVA (challenged). In the perfusate, thiobarbituric acid-reactive substances, 8-iso-PGF ${ }_{2 \alpha}$ and $\mathrm{PGE}_{2}$ were measured. Liver lobes after removal were used for the detection of total GSH as described in the Materials and methods.

an intraperitoneal injection of $10 \%(\mathrm{w} / \mathrm{v})$ urethane $(2 \mathrm{ml} / 100 \mathrm{~g}$ body weight). When a sufficient level of anaesthesia was achieved, a $2 \mathrm{~cm}$-long polyethylene tube (inner diameter $1.67 \mathrm{~mm}$, outer diameter $2.42 \mathrm{~mm}$ ) was inserted into the trachea, and the abdominal cavity was opened to inject $500 \mathrm{IU} / \mathrm{ml}$ of heparin into the vena cava and the abdominal aorta $3 \mathrm{~min}$ later. Thereafter, the thoracic cavity was opened to remove heart and lungs en bloc. The lungs were dissected free and hung in a plexiglass box at $37^{\circ} \mathrm{C}$ and $100 \%$ relative humidity. The lungs were perfused via the tracheal cannula with a phosphate-buffered physiological solution ( $\mathrm{pH} 7 \cdot 4)$ of the following composition: $137 \mathrm{~mm}-\mathrm{NaCl}, \quad 1.8 \mathrm{~mm}-\mathrm{CaCl}_{2}, \quad 1.05 \mathrm{~mm}-\mathrm{MgCl}_{2}$, $2.68 \mathrm{~mm}-\mathrm{KCl}, \quad 0.6 \mathrm{~mm}-\mathrm{NaHCO}_{3}, \quad 0.13 \mathrm{~mm}_{-}-\mathrm{NaH}_{2} \mathrm{PO}_{4}$ and $0.896 \mathrm{~mm}^{-\mathrm{Na}_{2}} \mathrm{HPO}_{4}$. The buffer was warmed to $45^{\circ} \mathrm{C}$ and pumped at a rate of $2 \mathrm{ml} / \mathrm{min}$ through a bubble trap before being cooled to $37^{\circ} \mathrm{C}$ for the actual lung perfusion. When the lungs had fully expanded, the buffer was allowed to exit the lungs through multiple small holes made in the pleura. The 'back pressure' resulting from the perfusion (airway opening pressure) was recorded from a side tap at the tracheal cannula with the use of a pressure transducer. We have previously shown that during continuous flow, the airway opening pressure reflects the contractile state of the lung ${ }^{(5)}$. Subsequently, lungs were perfused for $10 \mathrm{~min}$ to give a stable baseline pressure. For the induction of an early asthmatic response, $3.0 \mathrm{mg}$ ovalbumin in $0.30 \mathrm{ml}$ perfusion buffer was injected in the perfusion system as described earlier ${ }^{(5)}$.

\section{Effluent analysis}

Buffer that exited the lungs during the development of contractile responses was collected. In the case of non-sensitised animals, buffer was collected at the corresponding time. Samples were snap-frozen in liquid $\mathrm{N}_{2}$ and stored at $-80^{\circ} \mathrm{C}$ until analysis. Within 3 weeks after collection, the levels of $\mathrm{PGE}_{2}$, leukotrienes $\mathrm{C}_{4} / \mathrm{D}_{4} / \mathrm{E}_{4}$ and 8-iso-PGE $\mathrm{P}_{2 \alpha}$ were measured in the samples using commercial enzyme immunoassay kits (8-iso-PGF $2 \alpha$; Cayman, Ann Arbor, MI, USA; PGF $_{2}$ : Amersham Pharmacia Biotech, Uppsala, Sweden) according to the 
manufacturers' instructions. Samples $(100 \mu \mathrm{l})$ for the measurement of thiobarbituric acid-reactive substances (TBARS) were acidified to $\mathrm{pH} 2-3$ with $10 \mu \mathrm{l}$ of $1 \%(\mathrm{w} / \mathrm{v})$ TCA. Protein was precipitated by centrifugation, and $100 \mu$ l of the supernatant was allowed to react with an equal volume of thiobarbituric acid $(0.67 \%, \mathrm{w} / \mathrm{v})$ for $10 \mathrm{~min}$ at $100^{\circ} \mathrm{C}$. After cooling to room temperature, the absorbance at $532 \mathrm{~nm}$ was measured photometrically ${ }^{(13)}$. Perfusion buffer was treated in the same way to serve as a blank control.

\section{Serum IgG}

Blood samples $( \pm 350 \mu \mathrm{l}$ each) were collected from a femoral vein on days $-2,5,12,18$ and 20 (Fig. 1). Blood was allowed to clot for $30 \mathrm{~min}$ at room temperature before being centrifuged at $20000 \boldsymbol{g}$ for $10 \mathrm{~min}$. Serum was collected and stored at $-20^{\circ} \mathrm{C}$ until analysis. $\mathrm{IgG}_{1}$ antibody responses to ovalbumin were assayed using an ELISA. Flat-bottom microplates (ninetysix-well plates; Maxisorp, Nunc A/S, Roskilde, Denmark) were coated with $100 \mu \mathrm{g}$ ovalbumin/ml buffer $\left(38 \mathrm{~mm}-\mathrm{Na}_{2} \mathrm{CO}_{3}\right.$ and $\left.43 \mathrm{~mm}-\mathrm{KH}_{2} \mathrm{PO}_{4} ; \mathrm{pH} 9.5\right)$ for $60 \mathrm{~min}$ at $37^{\circ} \mathrm{C}$. After washing with $0.05 \%$ Tween 20 in PBS, free binding sites were blocked with $1 \%$ bovine serum albumin (Boehringer Mannheim, Phoenix, AZ, USA) in ELISA buffer ( $50 \mathrm{~mm}$-Tris, $2 \mathrm{mm-EDTA,}$ $136.9 \mathrm{~mm}-\mathrm{NaCl}$ and $0.05 \%$ Tween $20 ; \mathrm{pH} 7.2$ ) for $60 \mathrm{~min}$ at $37^{\circ} \mathrm{C}$. After removal of the blocking buffer and washing, serially diluted serum samples were incubated for $2 \mathrm{~h}$ at $37^{\circ} \mathrm{C}$. After washing, the plates were incubated with horseradish peroxidase-conjugated goat anti-guinea-pig $\operatorname{IgG}_{1}$ and $\operatorname{IgG}_{2}$ (diluted 1:10 000 and 1:3000, respectively; Bethyl Laboratories, Montgomery, TX, USA) in ELISA buffer with $0.5 \%$ bovine serum albumin. After washing, $O$-phenylenediamine dihydrochloride $(0.4 \mathrm{mg} / \mathrm{ml}$; Sigma $)$ in PBS containing $0.012 \% \mathrm{H}_{2} \mathrm{O}_{2}$ was added. The reaction was stopped after $10 \mathrm{~min}$ through the addition of $4 \mathrm{M}-\mathrm{H}_{2} \mathrm{SO}_{4}$. Optical density was measured at $490 \mathrm{~nm}$ with a Titrek Multiscan (Flowlabs, Irvine, UK). Serum samples that had been pre-incubated (120 min at $\left.37^{\circ} \mathrm{C}\right)$ with UWPC $(25 \mathrm{ng} / \mathrm{ml})$ underwent the same procedure to control for cross-reactivity of ovalbumin-specific IgG with UWPC, using pre-incubation with a similar amount of ovalbumin as a positive control.

\section{Measurement of liver glutathione}

After lung isolation, a liver lobe was snap-frozen in liquid $\mathrm{N}_{2}$ from each animal to be stored at $-80^{\circ} \mathrm{C}$ until analysis. After removal, each lobe was crushed in liquid $\mathrm{N}_{2}$ using a mortar and pestle; the resulting powder was transferred to an Eppendorf tube, and a mixture of $1 \mathrm{M}-\mathrm{HClO}_{4}$ with $2 \mathrm{~mm}$-EDTA was added ( $1 \mathrm{ml} / 250 \mathrm{mg}$ powder). After vigorous vortex mixing, tubes were centrifuged at $5000 \boldsymbol{g}$ for $10 \mathrm{~min}$, and total GSH (reduced and oxidised) concentrations in the supernatants were determined using a modified version ${ }^{(14)}$ of the GSH reductase-5, $5^{\prime}$-dithio-bis-(2-nitrobenzoic acid) recycling assay according to Akerboom \& Sies ${ }^{(15)}$. Values were expressed as $\mathrm{nmol} / \mathrm{mg}$ tissue (wet weight).

\section{Data analysis and statistics}

Tracings reflected the increase in airway opening pressure as a function of time. For each animal, the area under the curve was calculated from 50 to $150 \mathrm{~s}$ after the addition of allergen to the buffer. If data were normally distributed, they were analysed using a one-way ANOVA followed by the least significant difference post hoc test for multiple comparisons. If data were not normally distributed, they were analysed using the Kruskal-Wallis test. $P$ values $<0.05$ were considered to reflect significant differences. Student's unpaired $t$ test was used when only two groups were compared with each other. From previous experiments, the minimum number of animals per group could be calculated to find a possible significant effect in airway responses.

\section{Results}

\section{Liver glutathione and serum IgG levels}

UWPC treatment significantly enhanced the levels of total GSH $(2.75(\mathrm{SD} 0.7) \mathrm{nmol} / \mathrm{mg}, n 16, P<0.05)$ in the liver as compared with water-fed guinea pigs (2.26 (SD 0.15) nmol/mg, $n$ 17). We did not measure GSH levels in the lungs, since in an earlier study, we have described that GSH levels decrease after ovalbumin challenge in a similar set-up ${ }^{(5)}$.

Ovalbumin-specific $\operatorname{IgG}_{1}$ antibodies could not be detected in sera from sham-sensitised animals (data not shown). In the sera of ovalbumin-sensitised animals, a time-dependent increase in ovalbumin-specific $\operatorname{IgG}_{1}$ was observed (Fig. 2). UWPC feeding of sensitised animals did not alter plasma $\mathrm{IgG}_{1}$ levels as compared with the sensitised water-fed group. Furthermore, pre-incubation of serum samples with UWPC did not affect the binding of serum $\operatorname{IgG}_{1}$ to ovalbumincoated plates, while pre-incubation with ovalbumin blocked the binding completely (data not shown).

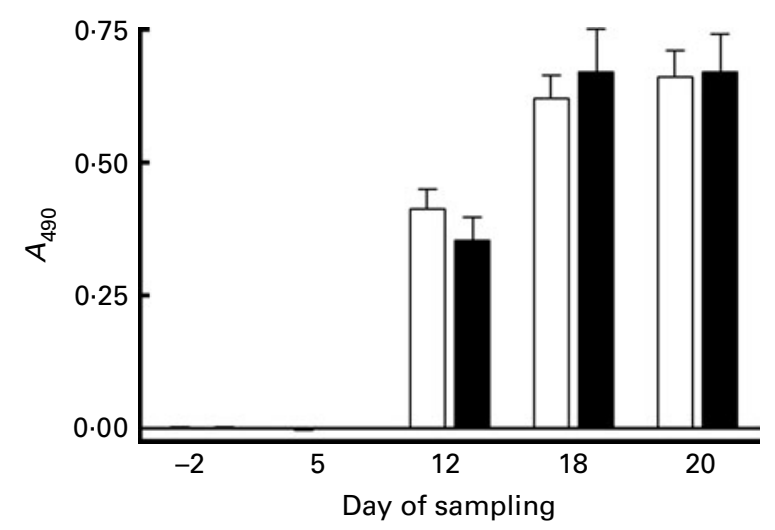

Fig. 2. Levels of serum $\operatorname{lgG}_{1}$ from water- and undenatured whey protein concentrate (UWPC)-fed guinea pigs. $\operatorname{lgG}_{1}$ levels in the 1280 -fold diluted serum of water-fed $(\square)$ and UWPC-fed ( $\square$ ) guinea pigs after sensitisation to ovalbumin. A time-dependent, but feeding-independent, increase in $\operatorname{lgG}_{1}$ levels was observed. Values are means, with their standard errors represented by vertical bars (water-fed group, $n$ 7; UWPC-fed group $n$ 8). No $\operatorname{lgG}_{1}$ was detectable in the saline-treated water-fed group $(n 9)$ or UWPC-fed group ( $n 9)$. $\mathrm{A}_{490}$, absorbance at $490 \mathrm{~nm}$. 


\section{Airway contractions}

In the lungs of the control animals, ovalbumin perfusion did not change airway opening pressure from either water-fed or UWPC-fed animals. In contrast, ovalbumin provoked a clear airway contraction in the lungs from sensitised animals (Fig. 3(A)). UWPC feeding reduced the allergen-induced airway contractions in sensitised animals by $45 \%$ as compared with sensitised animals that had received water as a control $(P<0 \cdot 05)$. Body weights did not change between the experimental groups during the feeding period.

\section{Effluent analysis}

It is known that oxidative stress induces the release of several allergy-associated mediators. Indeed, the levels of $\mathrm{PGE}_{2}$ dramatically increased in the perfusates of allergen challenge of the lungs of sensitised animals compared with non-sensitised animals $(P<0.05$; Fig. 3(B)). UWPC treatment decreased $\mathrm{PGE}_{2}$ levels in the perfusates of sensitised guinea-pig lungs by $55 \%$ as compared with the corresponding water-fed control group. This effect, however, did not reach statistical significance. Leukotriene concentrations were below the detection limit of the assay.

\section{Allergen challenge induces oxidative stress}

There were no macroscopical differences of the lungs between saline- and ovalbumin-treated animals. To investigate whether allergen challenge induced oxidative stress, 8-iso$\mathrm{PGF}_{2 \alpha}$ and TBARS were measured in the effluent of ovalbumin- or sham-sensitised (control) animals challenged with ovalbumin. Allergen challenge significantly increased 8-iso$\mathrm{PGF}_{2 \alpha}$ levels (22.02 (SD 1.23) pg/ml, P<0.01) compared with the saline group $(9.6(\mathrm{sD} 0.6) \mathrm{pg} / \mathrm{ml})$. Also, the levels of TBARS in the lung perfusate of sensitised animals were significantly elevated compared with the saline group (0.073 (SD 0.012) v. 0.041 (SD 0.005) optical density at $\left.\mathrm{A}_{532}, P<0.05\right)$.

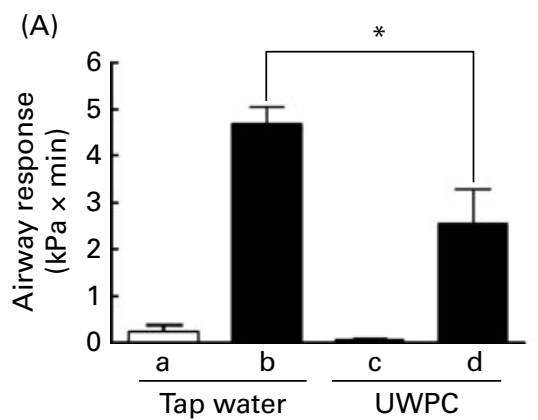

\section{Discussion}

We show for the first time that an anaphylactic bronchoconstriction is associated with oxidative stress, since $8-i s o-\mathrm{PGF}_{2 \alpha}$ was increased in the perfusate that was obtained during the anaphylactic constrictions of the airways. Besides being an indicator of oxidative stress, 8-iso- $\mathrm{PGF}_{2 \alpha}$ strongly constricts the airways ${ }^{(16-19)}$. In earlier studies, we have found that GSH decreases in the lungs during the early asthmatic reaction $^{(5)}$ and that GSH can decrease tracheal hyperreactivity to the contractile agent histamine ${ }^{(4)}$. In contrast, GSH depletion renders the airways to become hyper-reactive to this mediator $^{(20)}$. TBARS are endoperoxide breakdown products, but their formation does not require $\mathrm{GSH}^{(21)}$. TBARS levels were increased in the perfusate after ovalbumin challenge as well, giving further support that anaphylaxis is associated with oxidative stress indeed. Therefore, oxidative stress and/ or a decrease in antioxidants may lead to an enhancement in mediator release and/or the reactivity of the airways.

Furthermore, the present study demonstrates that UWPC food supplementation protects against early allergen-induced airway contractions in a guinea-pig model of allergic asthma. Since serum IgG levels were not affected by UWPC, the reduced airway contractions could not be explained by an effect of UWPC on sensitisation and, as a consequence, significant allergen-specific $\operatorname{IgG}_{1}$ levels, the antibodies that reportedly mediate immediate-type hypersensitivity in the guinea pig $^{(22)}$. Liver GSH, however, was increased by $20 \%$ by UWPC feeding, suggesting increased GSH levels in other tissues, including the lungs, as well. If so, UWPC treatment may have led to decreased allergen-induced contractions via a similar mechanism as perfusion with GSH or a GSH donor, which has been earlier shown to relax airway smooth muscle and prevent histamine- and allergen-induced airway contractions $^{(4,5)}$. Unfortunately, lung GSH levels could not be measured reliably with the methodology used in the present study, since the contractile state of the airway influenced the amount of buffer in the lungs, making it impossible to relate GSH content to tissue weight.

(1)

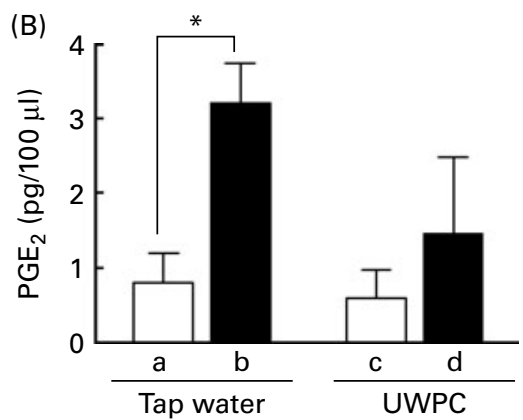

Fig. 3. Effects of undenatured whey protein concentrate (UWPC) on the allergen-induced early asthmatic airway contraction and PGE $\mathrm{E}_{2}$ levels in perfusate samples of the lungs. Values are means, with their standard errors represented by vertical bars. ${ }^{\star}$ Mean values were significantly different $(P<0.05)(A)$ Ovalbumin challenge induced contractions in the lungs from ovalbumin-sensitised guinea pigs ( $\square$ ), but not from saline-sensitised guinea pigs ( $\square$ ), but the ovalbumin-induced contractions were substantially reduced in the UWPC-fed group as compared with the water-fed group. Values are means, with their standard errors represented by vertical bars. * Mean values were significantly different $(P<0.05)$. Group a is significantly different from $b$, but not from $c$ and d. Group $b$ is significantly different from $c$ and d. Group $c$ is significantly different from d. (B) Ovalbumin challenge increased PGE $E_{2}$ formation in the lungs from ovalbumin-sensitised animals ( $\square$ ) as compared with saline-treated animals $(\square)$, but less so upon UWPC feeding. Group a is significantly different from b, but not from $c$ and d. Group b is significantly different from $\mathrm{c}$ but not from d. Group $\mathrm{c}$ did not differ from group d. 
The mechanism by which UWPC decreased the allergeninduced airway contractions is still unclear. The observation that an early asthmatic response is associated with decreased GSH levels and a disturbed reduced/oxidised GSH in guinea-pig lungs strongly suggested that allergen-induced airway contractions are accompanied by oxidative stress in the guinea pig ${ }^{(4,5)}$. This suggestion is substantiated by observations that two indicators of oxidative stress, 8-iso- $\mathrm{PGF}_{2 \alpha}{ }^{(23)}$ and $\operatorname{TBARS}^{(24)}$, were increased in the effluent of lungs during the early asthmatic response.

It is conceivable that allergen-induced oxidative stress modulates the production of mediators. Indeed, besides 8-iso-PGF ${ }_{2 \alpha}$, another cyclo-oxygenase metabolite, namely $\mathrm{PGE}_{2}$, was profoundly increased after ovalbumin challenge. Interestingly, in the UWPC-fed group, which had $20 \%$ higher GSH levels and a $40 \%$ decreased airway contraction, the $\mathrm{PGE}_{2}$ levels were decreased by $55 \%$. $\mathrm{PGE}_{2}$ production is known to be stimulated by oxidative stress ${ }^{(25)}$ and inhibited by a reactive oxygen species scavenger ${ }^{(26)}$. Additionally, it is known that $\mathrm{PGE}_{2}$ can dampen Th1 type of immune reactions leading to the up-regulation of the classical Th2-mediated allergy reaction. If $\mathrm{PGE}_{2}$ can be down-regulated, it might be very successful in skewing the immune response from Th2 towards Th1, which will lead to less severe allergic immune reactions with proteins.

This all suggests that oxidative stress probably contributes to the release of inflammatory mediators during anaphylaxis. Indeed, it has been shown by others that allergen-induced contractions of guinea-pig trachea were paralleled by histamine and $\mathrm{PGE}_{2}$ release ${ }^{(27)}$. The contractile mediators, histamine and leukotrienes, which are known to be released upon allergen-induced mast cell activation ${ }^{(28)}$ and whose release is potentiated by oxidative stress ${ }^{(29)}$, appeared hardly or not at all detectable in the perfusate of ovalbuminchallenged lungs from sensitised animals, regardless of the feeding. Possibly, the flow rate $(2 \mathrm{ml} / \mathrm{min})$ of the perfusion buffer has caused too much dilution of mediators to detect them in the perfusate.

In conclusion, we demonstrated that an early asthmatic reaction is associated with oxidative stress. Increasing endogenous GSH levels by UWPC largely prevented the anaphylactic airway constriction. UWPC did not influence the production of $\operatorname{IgG}_{1}$ and thus sensitisation to ovalbumin. Therefore, besides the mediators released from mast cells by cross-linking of $\operatorname{IgG}_{1}$, it is likely that the oxidative stress induces additional mediator release which can be inhibited by UWPC. This opens a new therapeutic area for patients with allergic diseases, who may benefit from a whey-enriched diet.

\section{Acknowledgements}

The present study was funded by the Division of Pharmacology and Pathophysiology, Utrecht Institute for Pharmaceutical Sciences, Utrecht University, The Netherlands. The authors have no conflicts of interest. J. K., N. B., E. M., F. P. N. and G. F. conceived and designed the experiments. J. K., E. M. and I. V. A. performed the experiments. J. K., E. M., N. B., J. G., F. P. N. and G. F. analysed the data. J. K.,
E. M., I. V. A., N. B. and G. F. contributed the reagents/ materials/analysis tools. J. K., E. M. and G. F. wrote the manuscript.

\section{References}

1. Henricks PA \& Nijkamp FP (2001) Reactive oxygen species as mediators in asthma. Pulm Pharmacol Ther 14, 409-420.

2. Dut R, Dizdar EA, Birben E, et al. (2008) Oxidative stress and its determinants in the airways of children with asthma. Allergy 63, 1605-1609.

3. Biswas SK \& Rahman I (2008) Environmental toxicity, redox signaling and lung inflammation: the role of glutathione. $\mathrm{Mol}$ Aspects Med 30, 60-76.

4. Kloek J, van Ark I, Bloksma N, et al. (2002) Glutathione and other low-molecular-weight thiols relax guinea pig trachea ex vivo: interactions with nitric oxide? Am J Physiol Lung Cell Mol Physiol 283, L403-L408.

5. Joris Kloek, Esmaeil Mortaz, Ingrid van Ark, et al. (2010) Glutathione prevents the early asthmatic reaction and airway hyperresponsiveness in guinea pigs. I Physiol Pharmacol 61, 67-72.

6. Anderson ME (1997) Glutathione and glutathione delivery compounds. Adv Pharmacol 38, 65-78.

7. Karlsen RL, Grofova I, Malthe-Sorenssen D, et al. (1981) Morphological changes in rat brain induced by L-cysteine injection in newborn animals. Brain Res 208, 167-180.

8. Olney JW, Ho OL \& Rhee V (1971) Cytotoxic effects of acidic and sulphur containing amino acids on the infant mouse central nervous system. Exp Brain Res 14, 61-76.

9. Cotgreave IA (1997) $N$-acetylcysteine: pharmacological considerations and experimental and clinical applications. Adv Pharmacol 38, 205-227.

10. Anderson ME \& Meister A (1983) Transport and direct utilization of gamma-glutamylcyst(e)ine for glutathione synthesis. Proc Natl Acad Sci U S A 80, 3, 707-711.

11. Lothian B, Grey V, Kimoff RJ, et al. (2000) Treatment of obstructive airway disease with a cysteine donor protein supplement: a case report. Chest 117, 914-916.

12. Lothian JB, Grey V \& Lands LC (2006) Effect of whey protein to modulate immune response in children with atopic asthma. Int J Food Sci Nutr 57, 204-211.

13. Esterbauer H \& Cheeseman KH (1990) Determination of aldehydic lipid peroxidation products: malonaldehyde and 4-hydroxynonenal. Methods Enzymol 186, 407-916.

14. Vandeputte C, Guizon I, Genestie-Denis I, et al. (1994) A microtiter plate assay for total glutathione and glutathione disulfide contents in cultured/isolated cells: performance study of a new miniaturized protocol. Cell Biol Toxicol 10, 415-421.

15. Akerboom TP \& Sies H (1981) Assay of glutathione, glutathione disulfide, and glutathione mixed disulfides in biological samples. Methods Enzymol 77, 373-382.

16. Held HD \& Uhlig S (2000) Mechanisms of endotoxininduced airway and pulmonary vascular hyperreactivity in mice [In Process Citation]. Am J Respir Crit Care Med 162, Pt 1, 1547-1552.

17. Bernareggi M, Rossoni G \& Berti F (1998) Bronchopulmonary effects of 8-epi-PGF2A in anaesthetised guinea pigs. Pharmacol Res 37, 1, 75-80.

18. Janssen LJ, Premji M, Netherton S, et al. (2000) Excitatory and inhibitory actions of isoprostanes in human and canine airway smooth muscle. J Pharmacol Exp Ther 295 $506-511$. 
19. Wang S, Young RS \& Witten ML (2001) Age-related differences in pulmonary inflammatory responses to JP-8 jet fuel aerosol inhalation. Toxicol Ind Health 17, 23-29.

20. Phimister AJ, Lee MG, Morin D, et al. (2004) Glutathione depletion is a major determinant of inhaled naphthalene respiratory toxicity and naphthalene metabolism in mice. Toxicol Sci 82, 268-278.

21. Meagher EA \& FitzGerald GA (2000) Indices of lipid peroxidation in vivo: strengths and limitations. Free Radic Biol Med 28, $1745-1750$.

22. Fraser DG, Graziano FM, Larsen CP, et al. (1998) The role of $\mathrm{IgG}_{1}$ and $\mathrm{IgG}_{2}$ in trimellitic anhydride-induced allergic response in the guinea pig lung. Toxicol Appl Pharmacol 2, 218-227.

23. Roberts LJ \& Morrow JD (2000) Measurement of F(2)-isoprostanes as an index of oxidative stress in vivo. Free Radic Biol Med 28, 505-513.
24. Aghdassi E \& Allard JP (2000) Breath alkanes as a marker of oxidative stress in different clinical conditions. Free Radic Biol Med 28, 880-886.

25. Becker S, Madden MC, Newman SL, et al. (1991) Modulation of human alveolar macrophage properties by ozone exposure in vitro. Toxicol Appl Pharmacol 110, 403-415.

26. Brigham KL, Meyrick B, Berry LC Jr, et al. (1987) Antioxidants protect cultured bovine lung endothelial cells from injury by endotoxin. I Appl Physiol 63, 840-850.

27. Whigham LD, Cook EB, Stahl JL, et al. (2001) CLA reduces antigen-induced histamine and PGE(2) release from sensitized guinea pig tracheae. Am J Physiol Regul Integr Comp Physiol 280, R908-R912.

28. Barnes PJ, Chung KF \& Page CP (1998) Inflammatory mediators of asthma: an update. Pharmacol Rev 50, 515-596.

29. Masini E, Palmerani B, Gambassi F, et al. (1990) Histamine release from rat mast cells induced by metabolic activation of polyunsaturated fatty acids into free radicals. Biochem Pharmacol 39, 879-889. 